\title{
Using the World Wide Web to promote educational discussion on university level courses
}

\author{
P. Hietala, T. Niemirepo and S. Ovaska \\ University of Tampere, Department of Computer Science \\ P.O. Box 607, FIN-33101 Tampere, FINLAND \\ e-mail:\{ph,tkn,ov\}@cs.uta.fi
}

\begin{abstract}
In this paper we describe our efforts in promoting educational discussion and collaborative work on university level courses. This research has been carried out in a research project entitled "Conferencing on the Web for Group Learning" (CoWoGLe project). The goal of the project is to augment the participation in and quality of educational discussion by using Web-based computer conferencing. We also aim at producing systems easily tailorable for use in various course settings, to suit different learning and teaching approaches. In this paper we report on our first efforts in this direction, by outlining the theoretical background of our work and the two prototype systems designed and implemented in the project. We provide empirical data describing the use of our systems on four courses with more than 200 students. We also indicate how our systems have evolved during the field experiments and end with a few suggestions for further work.
\end{abstract}

\section{Keywords}

Distributed learning system, Tools for distance education, Web-based conferencing systems 


\section{INTRODUCTION}

The problems in university level higher education are well known. First, the ratio of students per teacher is growing, for both on-campus students and those studying at distance while working. Secondly, traditional methods of teaching (such as lectures) have been heavily criticized as old-fashioned and non-efficient from the point of view of modern educational theory. The larger number of students makes it difficult to abandon the traditional approaches, though. Evidently, the opportunities for fruitful discussion between the teacher and the student are diminishing (Mayes \& Neilson, 1995). Yet, as Laurillard (1993) has pointed out, dialogue lies at the heart of the educational experience, and has been an essential part of higher education in the past.

Dialogue, not only with teachers, but also with peer learners, is very important in learning, thus collaborative learning should have a prominent role in higher education. Any university should prepare its students for teamwork situations common in the workplaces of today, by providing team and project work opportunities. Typically, these opportunities are associated with lab work (as in computer science), but even lectures could be alternatively organized as collaborative learning events (Yerion \& Rinehart, 1995). Still, the demand for more discussion, collaboration and group work in higher education may cause problems for those students who do not fit the 8 to 4 university day, e.g., extension or graduate students, or students working outside the university.

The use of telecommunications seems one promising solution to the problems outlined above. In fact, textual Computer Mediated Communication (CMC) and computer conferences have already been used as means of organising group discussions and distance education (Turoff, 1991). There are many commercial systems available today, but many of these systems are too expensive for schools or universities and some are also somewhat difficult to learn to use (Klemm \& Snell, 1994).

Recently, the World Wide Web has been marketed as the panacea for most of the problems in education, also for those in higher education. Most uses of the Web so far, however, concentrate on how to organize and present information content on the Web pages or how to find the latest material created by others. For our purposes, we would like to explore more the use of the Web to support educational discussion. Some researchers (Reeves, 1997) even suggest that Web-based tools for groupwork and collaboration are potentially the most powerful factors of the Web in promoting learning. Already tens of Web-based discussion forums have been developed (Woolley, 1997). However, not many are in use in higher education on a regular basis and even fewer have been analyzed or evaluated.

In order to study these issues we have implemented experimental discussion forums with varying support for structured discussion, and introduced them in several courses in our department (four courses with more than 200 students). In this paper we focus on the field experiments we have conducted so far, and report 
mainly on qualitative findings concerning the discussion forum used in each case. We also indicate how these systems have evolved during the experimentation period and end with a few suggestions for further work.

\section{RELATED WORK AND BACKGROUND}

Mayes and Neilson (1995) describe learning as a cycle of stages leading to the growth of understanding. In this model learning starts with conceptualisation where the exposition of material to be learned is important. Most educational programmes (primary courseware) are concentrating on this aspect. Although there is a shift from this kind of instructivist learning, in the direction of providing exploratory and constructivist environments, programmes of the latter kind (secondary courseware) are not very common. Finally, the third stage of learning (called dialogue) shapes and re-organizes the material learned through discussion, mutual questioning and reflection in a social environment (the learner together with peers and the teacher). In this paper our goal is to consider especially those educational environments assisting the dialogue stage of learning (tertiary courseware). Furthermore, how to assist more than one of these three stages in one learning environment emerges as an important research question.

For there are many possibilities the assisting the dialogue as defined above. On the one hand, the more expensive groupware systems (e.g., Lotus Learning Space $^{\mathrm{TM}}$ ) integrate all the three stages presented above but may not offer much scaffolding for the third stage. At the other end, standard network tools, such as email, bulletin boards, and news groups are useful in enhancing discourse. However, there are also problems (Klemm \& Snell, 1996): for example, in many mailing systems sequencing and structuring is non-existent, all messages are intermingled, switching between private and public is not easy, and lacks the media of graphics and photos. Bulletin boards (news groups) are more user friendly than e-mail and have some organization of content but there are problems with poor graphics, linking to older messages, and other means of supporting dialogue.

One problem with standard network tools is that their support typically concerns only the social aspects of communication. We believe that both cognitive and social perspectives should be scaffolded in the educational use of computer mediated communication. By the cognitive aspects we mean that the systems should provide some structure that scaffolds or guides the discussants. Structured discussion can be established, e.g. by requesting that the students indicate the type of their messages, or the source from where they have obtained their arguments. The support for cognitive processes can be domain dependent or independent. One source that can build the basis for the design of domain independent support are the theories of problem solving and critical thinking (Newman et al., 1995; Mason, 1991). After all, the abilities of critical thinking, evidently, are an integral part of the "pedagogical residue" that our students should carry with them when leaving the university. 
Of the similar approaches to support argument and group work we can mention e.g. systems like CSILE (Scardamalia \& Bereiter, 1993), or The Collaborative Notebook in the CoVis project (O'Neill et al., 1995), but many of them are for preuniversity levels and some basically LAN solutions. As for the university level solutions, we can mention e.g. WebCamile (Turns et al., 1995), FORUM (Klemm $\&$ Snell, 1996) and the work of Verdejo et al. (1996). Most of these are more oriented towards supporting collaborative design and problem-solving than just conferencing. However, not much empirical evidence has yet been published on the use of these systems.

An interesting idea is to save the discussion as a knowledge base for later student inspection (e.g. to alleviate next year's students familiarization with systems and topics of the course). The Axis system (Chaplin, 1996) has this kind of knowledge base incorporated. A related project is AnswerWeb (Mayes \& Neilson, 1995), an attempt to accumulate a knowledge base of question-answer pairs connected to simulations of engineering phenomena. In this kind of approach locating relevant information is of utmost importance (even if questions with no earlier answers are routed to lecturers). It would be very interesting to have empirical evaluation studies of this approach.

\section{THE COWOGLE PROJECT AT THE UNIVERSITY OF TAMPERE}

The CoWoGLe (Conferencing on the Web for Group Learning) project has set out to study existing (Web-based) computer-conferencing systems, build lightweight conferencing systems that can be used with ordinary Web browsers, and experiment on the conferencing systems as part of course work. Our main motivation is pragmatic: we want to collect experience on different ways of integrating a computer-conferencing forum as part of course work, and learn about the user requirements of students and teachers using the software. As we already have interest in both CSCL and CSCW at our department this seemed a fruitful starting position for a project (of the need of research synergy for these two research communities see Collis (1994)).

In our experiments we have varied several aspects of the use: course goals and assignments, the properties of our conferencing systems and means of adding structure to the discussion. As the settings vary a lot from course to course, we do not aim at providing any conclusions or generalizable results at this point. Instead, we hope to elaborate on our ideas and eventually develop good strategies for integration of the conferencing software meaningfully into course arrangements for the benefit of both learners and teachers.

\section{Course assignments}

In some courses the use of the computer-conferencing software has been mandatory to a certain extent (number of messages sent), while in other courses the usage has been voluntary. We have experimented with the length of the time period devoted to commenting so that in some cases the students have had two weeks of 
time to work out their comments in the system, in some cases only a couple of days. The assignments have been different in all courses ranging from broad discussion topics to more group work oriented problem solving exercises. Also voting tasks have been used. In some courses we have restricted the length of the individual postings and the student's possibilities to create new discussion topics. The conferencing has so far been only one part of the courses, we have not yet tried to build a course based entirely on the Web.

\section{Adding structure to discussions}

As we wish to promote meaningful and structured discussion, we have also varied several aspects of the conferencing systems. One way of adding structure to the discussion is to give a set of annotation types for the user to select from before (or after) writing his/her annotation. The discussion topics have been specified together with a set of annotation types. Thus the number and nature of annotation types may vary even between topics in the same discussion forum. Another way of adding structure is to ask the user to specify the source of the annotation, for instance, lectures, other literature, or a personal opinion.

\section{Versions of the conferencing systems}

The CoWoGLe project has so far developed two versions of a computerconferencing system: $3 \mathrm{Wcomments}$ and Dyn $3 \mathrm{~W}$. The prototypes differ mainly in their user interface: $3 \mathrm{~W}$ comments does not use frames while Dyn3W does, and Dyn $3 \mathrm{~W}$ uses folders to encapsulate branches of the annotation tree while in $3 \mathrm{~W}$ comments the leaves are shown all the time. Both systems keep track of the poster's and reader's identity. Also, both systems allow anonymous annotations where the poster's identity is not revealed to other readers but only to the teacher. We have also built tools for the teacher to analyse and keep track of the activity of the students.

The development of the systems is ongoing, and sometimes even in the middle of a course we have switched to a new version or to the other conferencing system. This enables us to leam about user reactions to analyse the usability of the system. The system versions are always tailored to suit the course at hand.

Next we outline briefly the two systems implemented at the University of Tampere. Both prototype systems are implemented using CGI programming in standard Web browsers.

\subsection{Wcomments}

The $3 \mathrm{Wcomments}$ system has a standard Web interface where new pages are retrieved after clicking hotwords or buttons on a page. Each topic in $3 \mathrm{Wcomments}$ (see Figure 1) has a title, a short description with perhaps a link to an interesting web-page, and information about the author of the topic and date. In this paper we will use the word "annotation" for all user contributions (sometimes in the literature also called comments, notes, or messages). A button for adding an annotation to the topic is located under the topic, and the annotation is written into 
a form. The type of the annotation is chosen after the annotation text has been written, and it may also be left empty. Each individual annotation in the annotation tree may be commented in the same way: clicking on the title of the annotation shows the text of it, and associated is a button for adding an annotation. The underlined author names are mailto-links for individual feedback.

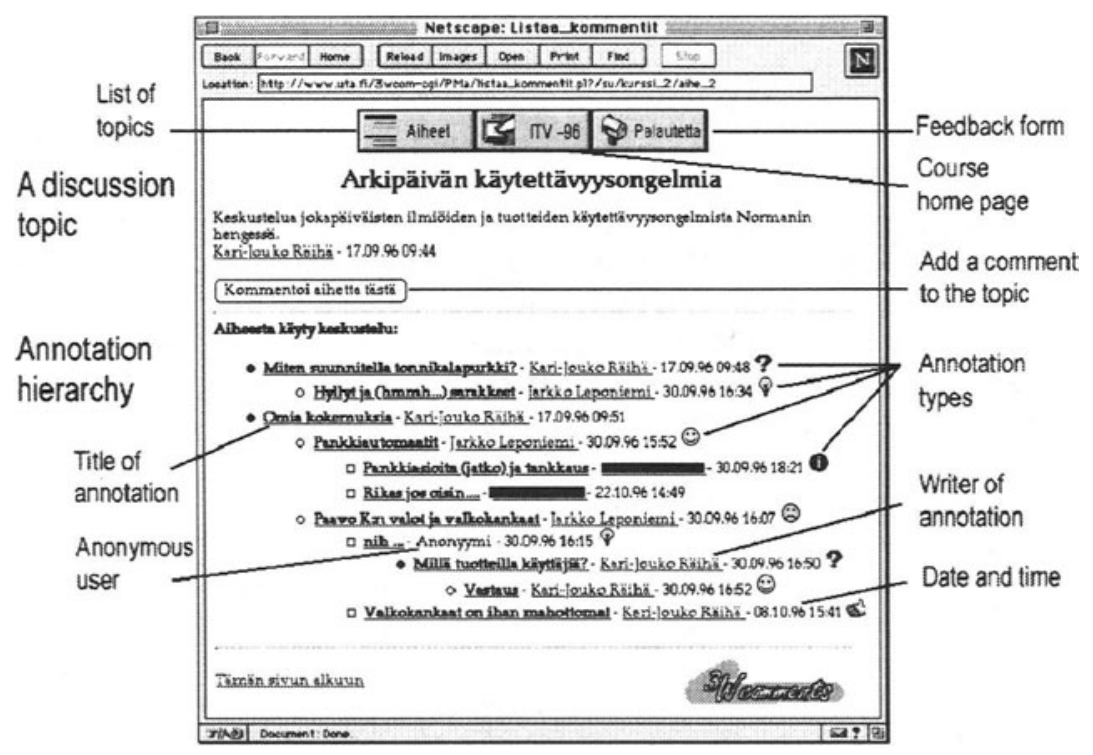

Figure 1. A discussion tree in $3 \mathrm{Wcomments.}$

\subsection{Dyn3W}

The Dyn3W system utilizes frames to divide the interface into different parts in such a way that is supposed to help the user to better perceive and participate in the discussion. The frames make it possible to show the annotation hierarchy in one frame while the selected annotation can be read in another frame (see Figure 2). When adding an annotation, the frame on the right side is split into two parts. The frame for writing the annotation is located at the bottom of the right side. The top right hand side frame can be used for reading the other annotations as well as previewing one's own annotation before saving it.

Dyn3W tries to help the user to clarify his/her argumentation by forcing $\mathrm{him} /$ her to select the type of the annotation before he/she can write it. For the same reason, the user has in some Dyn $3 \mathrm{~W}$ versions to determine the source for his/her argument before the annotation is saved. When adding a topic one must define the title, the text, the annotation and source types and optionally an http-link to some essential source. The topic can be defined to be open to everyone or for the named participants only. For the annotation one must define the type of the annotation and the source of the argument the title, the text and optionally an http-link. Before the 
annotation is saved the system checks the compulsory parts and gives an error message if something is missing. Only after the annotation is in order it is saved. The annotation can not be changed afterwards but the user may cancel it before it is saved.

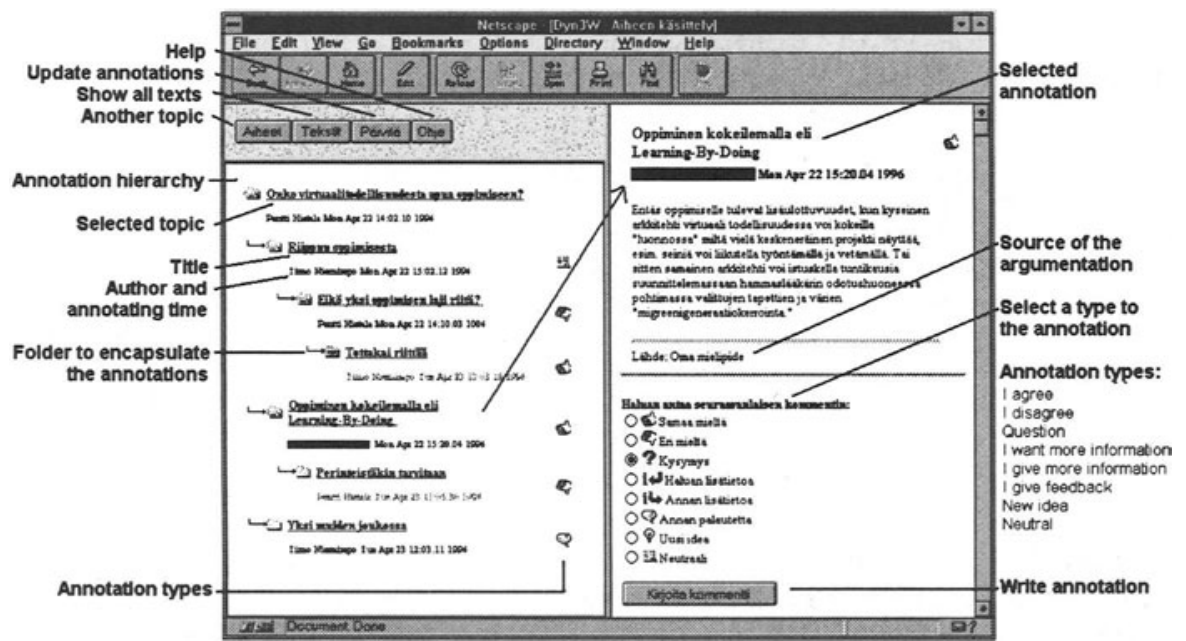

Figure 2. Working with a selected topic in Dyn3W.

\section{FIELD EXPERIMENTS WITH THE SYSTEMS}

In the academic year 1996-97, the systems described in the previous chapter were in use at our department on four courses (and a seminar, which is not reported here). The goals for the system use varied from course to course. Two courses (see Table 1) utilized the discussion forum to support free discussion, while the other two had more obligatory assignments to be worked on with the system.

Because the courses were given by the Department of Computer Science, most of the students were majoring in computer science or mathematics. However, many of the students participating were non-science undergraduates, e.g., from education, psychology, literature or information science. None of the courses is mandatory to the participating students, except the Computer Aided Instruction course for those mathematics students majoring to become teachers in mathematics. 


\begin{tabular}{|c|c|c|c|c|}
\hline Course & Course topic & $\begin{array}{c}\text { Main goal for } \\
\text { conferencing system } \\
\text { use }\end{array}$ & $\begin{array}{l}\text { How conferencing } \\
\text { systems were used }\end{array}$ & Students \\
\hline $\begin{array}{l}\mathrm{HCI} \\
\text { Fall } 96\end{array}$ & $\begin{array}{l}\text { Human Computer } \\
\text { Interaction }\end{array}$ & $\begin{array}{l}\text { Free discussion, mainly } \\
\text { on interface issues }\end{array}$ & voluntary & $\begin{array}{l}\text { 2nd year, mainly } \\
\text { Comp. Sci. }\end{array}$ \\
\hline $\begin{array}{l}\text { Groupware } \\
\text { Spring } 97\end{array}$ & $\begin{array}{l}\text { Groupware and } \\
\text { CSCW Systems }\end{array}$ & $\begin{array}{l}\text { Exploration of various } \\
\text { groupware systems }\end{array}$ & voluntary for credits & $\begin{array}{l}\text { 3rd or } 4 \text { th year, } \\
\text { mainly Comp. } \\
\text { Sci. }\end{array}$ \\
\hline $\begin{array}{l}\text { CAI } \\
\text { Fall } 96\end{array}$ & $\begin{array}{l}\text { Computer-Aided } \\
\text { Instruction }\end{array}$ & $\begin{array}{l}\text { Discussion on CAI } \\
\text { topics }\end{array}$ & $\begin{array}{l}\text { obligatory } \\
\text { ( } 5 \text { comments) }\end{array}$ & $\begin{array}{l}\text { extension } \\
\text { students }\end{array}$ \\
\hline $\begin{array}{l}\text { CAI } \\
\text { Spring } 97\end{array}$ & $\begin{array}{l}\text { Computer-Aided } \\
\text { Instruction }\end{array}$ & $\begin{array}{l}\text { Structured work in } \\
\text { small groups, after } \\
\text { which public discussion } \\
\text { on results of small } \\
\text { group work }\end{array}$ & $\begin{array}{l}\text { obligatory ( } 1 \text { own } \\
\text { suggestion) plus } \\
\text { credit from extra use }\end{array}$ & $\begin{array}{l}\text { 1st or } 2 \text { nd year, } \\
\text { mainly Comp. } \\
\text { Sci. Also various } \\
\text { non-science } \\
\text { students }\end{array}$ \\
\hline
\end{tabular}

\section{Table 1 Courses in a nutshell}

Table 2 presents an overview of the systems used in each course. In the following chapters these courses are elaborated on together with our preliminary findings. The analysis of the four courses varies because the corpus of data collected varied from course to course. In this paper we report mainly on issues concerning the usability of the systems and on the support for argumentation and annotation. A more thorough analysis of the collaboration, including content analysis of the annotations, will follow in a later paper.

\begin{tabular}{|c|c|c|c|c|c|}
\hline $\begin{array}{l}\text { Course, } \\
\text { semester }\end{array}$ & Systems used & $\begin{array}{l}\text { Number } \\
\text { of } \\
\text { students }\end{array}$ & $\begin{array}{l}\text { Styles of } \\
\text { conferencing }\end{array}$ & $\begin{array}{l}\text { Possibility } \\
\text { to create } \\
\text { own topics }\end{array}$ & $\begin{array}{c}\text { Privatel } \\
\text { public } \\
\text { discussion space }\end{array}$ \\
\hline $\begin{array}{l}\mathrm{HCI} \\
\text { Fall } 96\end{array}$ & $\begin{array}{l}3 W \text { comments } \\
\text { Dyn3W }\end{array}$ & 83 & $\begin{array}{l}\text { - annotating } \\
\text { - voting }\end{array}$ & Yes & - public \\
\hline $\begin{array}{l}\text { Groupware } \\
\text { Spring } 97\end{array}$ & Dyn3w & 40 & $\begin{array}{l}\text { - annotating } \\
\text { - voting }\end{array}$ & yes & - public \\
\hline $\begin{array}{l}\text { CAI } \\
\text { Fall } 96\end{array}$ & Dyn3w & 21 & - annotating & no & - public \\
\hline $\begin{array}{l}\text { CAI } \\
\text { Spring } 97\end{array}$ & Dyn3w & 76 & $\begin{array}{l}\text { - annotating } \\
\text { - working in } \\
\text { small groups } \\
\text { - voting }\end{array}$ & restricted & $\begin{array}{l}\text { - private } \\
\text { - public }\end{array}$ \\
\hline
\end{tabular}

Table 2 Systems in use on the four courses 


\subsection{HCI Fall 1996 with 3Wcomments and Dyn3W}

\section{Background and goals}

Our hypothesis was that the discussion forum could be useful in promoting discussion on topics introduced in the lectures. The discussion forum could also be used for questions and guidance about the large Web-based development assignment the course included. The assignment was rarely discussed during the lectures. The students (83) were introduced to both of our prototype conferencing systems in order to provoke discussion on the interface issues.

\section{Usability}

The first system in use was $3 \mathrm{Wcomments,} \mathrm{and} \mathrm{in} \mathrm{November} \mathrm{(after} \mathrm{seven} \mathrm{weeks} \mathrm{of}$ use) the contents of the still valid discussion topics were moved to Dyn3W. The new forum increased the number of comments written about the system features.

The frames received most negative feedback. Three frames on a small screen made scrolling a necessity, and especially the space reserved for writing one's own annotations was considered too small. Opinions concerning positive aspects were given too: the frames enabled staying on the same screen while reading the annotations, since only one frame was updated at a time.

Folders in Dyn $3 \mathrm{~W}$ were liked by most students, since they allow some branches of the annotation tree to be encapsulated and thus make the tree smaller. The issue of obligatory selection of an annotation type in Dyn $3 \mathrm{~W}$ was brought up only in one negatively toned comment.

\section{Scaffolding argumentation and annotation}

Our expectations about promoting discussion in $3 \mathrm{Wcomments}$ and Dyn $3 \mathrm{~W}$ were not met. The discussion topics were set by the lecturer about issues related to the lectures, but they did not receive more than a couple of student annotations. The students raised five topics themselves, and these topics dealt with different aspects of the assignment. We tried several means of promoting the use of the discussion forum, for instance by setting up a topic of extra exercise groups with enrolment as annotations in the discussion forum. Also a poll was organised at the end of the course using Dyn $3 \mathrm{~W}$. The students were asked to vote on the best Web service developed in the course. To our surprise, at this late stage still some students logged on the conferencing system for the first time. Apparently the poll task was motivating for the students, and we received about 20 votes; but many more students read the voting task options in Dyn $3 \mathrm{~W}$.

A minority (39 students, $47 \%$ ) of the 83 students attending the course were somehow active (by voting, enrolling, etc.) in the new forum. If we exclude the discussion promoting tasks, an annotation was written by 14 students, six of which contributed only anonymously. Anonymity was felt to be an important feature of the system also by the six students who filled in a questionnaire presented them in Dyn3W.

The experiences we had on the HCI course brought clearly forward the need to motivate students to participate in a public discussion. The objectives of the shared 
discussion forum were not presented to the students in a manner promoting shared benefit; instead, the forum was mainly used for public administrative announcements and detailed questions about the difficulties in the assignment. Total freedom in taking part in the discussion meant that the more urgent affairs were given precedence. The gains for the students of devoting their time to the discussion forum were not high. A clearer coupling between the lecture material and the discussion forum would be needed to enable discussion on each individual issue in the material, and when new annotations or topics appear in the system, the users' attention should be triggered, for instance, by e-mailing them, to start using the system.

\subsection{Groupware Spring 1997 with Dyn3W}

\section{Background and goals}

Dyn3W was only one of the groupware systems (like BSCW and TeamWave, among others) tried out during the course. One goal was to provide the students (40) with both theoretical knowledge and hands-on experience on the major design and evaluation issues of groupware systems. As in the $\mathrm{HCI}$ course, all participation was voluntary but active participation was credited. The students were able to write new discussion topics, and comment on the earlier ones. Also votes were collected on several issues.

\section{Usability}

The user interface of Dyn3W was criticized by some students: "Discussion with the system is rigid. It is annoying to read the messages. Since they are short, you end up clicking fast when following the links. It is difficult to comprehend the annotation space." As one possible solution, another arrangement of the three frames was presented and adopted during the course. In this version all the three frames were placed under each other, the annotation hierarchy above the frame for showing the annotation text. The placement received only two comments, the first stating the user should be able to select the orientation of the frames, and the other complaining about unnecessarily showing the annotation hierarchy even while writing the annotation.

\section{Scaffolding argumentation and annotation}

A spontaneous discussion emerged in Dyn3W about the benefits and drawbacks of anonymity. The students took opposite stands about the value of knowing who is the writer of an annotation. Two opposing annotations:

- "... I do not have the energy to read anonymously written comments..." and, later: "... There's nobody backing up an anonymous comment.", and, "...in the real world, it appears that a person has more weight than another."

- "I do not evaluate an annotation regarding if it has been written anonymously or not. In a conferencing system, most people are anyhow totally unknown."

A poll was organized by one of the students who took part in the discussion. He posted the results of the poll: 1 student voted to abandon all anonymity, 2 students 
admitted they read also anonymous postings but do not give much value to them, 1 student said that all writings are equally valuable, and the majority of 5 students admitted reading and sometimes even thinking about the contents of anonymous annotations.

\subsection{CAI Fall 1996 with Dyn3W}

\section{Background and goals}

The course on Computer-Aided Instruction is typically taken by first or second year students. However, the Fall 96 course was organized at the Institute for the Extension Studies within our university. The students were adults from working life extending or continuing their earlier studies, and so the course was organized a little differently, e.g. the lectures took place in the evenings and during weekends.

Dyn $3 W$ was used for three weeks by 21 students. This was the first time Dyn $3 \mathrm{~W}$ was in real use and the goal was to find out how usable the system was and how the support for discussion was received. Three topics relating to the theme of the course were given. To pass the course a student had to write at least five annotations. After the fifth annotation the system presented a questionnaire. We report some data from the questionnaire conceming the usability of the system.

\section{Usability}

Dyn $3 \mathrm{~W}$ was found easy to use by $81 \%$ of the students and $76 \%$ felt that discussion with Dyn3W was pleasant. In free feedback they stated, e.g. that "You don't hove to be dependent on the time and place" (subject 1) and "In this way everyone has the opportunity to express his opinion" (subject 17). The students liked that they were able to plan their contributions in peace and when they have an opinion they have a chance to expose it. The main obstacle seemed to be the fact that the frames left too little room for the contents, e.g. "Quite small windows ... scrolling gets quite annoying sometimes" (subject 14) and "... it is difficult to write to the annotation window because of its small size" (subject 17).

\section{Scaffolding argumentation and annotation}

The most used annotation type for the first three annotations was "I agree" (39.7 $\%)$ and the next two were "I give feedback" (22.2\%) and "Neutral" (12.7\%). For the three next annotations the most used annotation types were " $I$ agree" and " $I$ give feedback" (both $25.0 \%$ ) and then came "Question" (16.7 \%). It is noticeable that the "Question" and "I give feedback" types increased their popularity. Perhaps we can draw such a conclusion that after the preliminary phase the system encouraged the participants to demand more information and to give their own contributions to the discussion.

At the beginning the most used source for the argumentation was "My opinion" (68.3\%) and the next were "Conversation with other" $(9.5 \%)$ and "The Media" $(6.3 \%)$. At the later stage "My opinion" is still the most used $(54.2 \%)$ but " $M y$ idea" (14.6\%) had taken the second place and "Common fact" and "Conversation 
with other" (both $10.4 \%$ ) took the third place. It seems that taking part in a public discussion where the annotations remain to be read by other participants creates a reluctance to give to the others the possibility to verify the argument with the help of some precise source. An own idea or opinion is always a safe source because they can be based on the prevailing feelings that can be changed later on.

The possibility of reading other annotations at the time of writing one's own annotation was found to be a helpful feature by $76 \%$ of the students. Note that in the Groupware Spring 1997 course this possibility was considered as unnecessary by one student.

This experiment made us suspect that an open discussion without any specified structure or goal would not be a fruitful arrangement to promote educational discussion. In the next experiment we used a well-defined assignment with a more strict time schedule.

\subsection{CAI Spring 1997 with Dyn3W}

\section{Background and goals}

The Computer Aided Instruction course in Spring 1997 was attended by 76 students, mainly from Computer Science and Mathematics. In this course we wanted to analyse the support for group work and learning, not only public discussion among all students. The goal for this experiment was to find out what effect does Dyn $3 \mathrm{~W}$ have on the development of the critical thinking of the students. A further analysis will be made by examining the changes in the contents of the annotations. However, in this paper we only report on the issues concerning the usability and support for annotation.

\section{Assignment}

The students were divided into ten groups each with the goal to produce one solution for a given task. Every group had its own private discussion space in Dyn3W, where each member of the group had to prepare his/her own suggestion for the solution and other members commented by giving " $A$ good feature" or " $A$ weak feature" annotations. After a one week annotating period every group voted for the best solution and the winning solution (polished by its author) was published so that the other groups could comment it. The work was structured by a strict schedule and by forcing the solutions to be given in a certain form. Furthermore, there were only two types of annotation that could be given, and the source of argument had to be defined. To pass the course a student had to give at least one solution and if he/she wanted to gain extra points he/she had to give at least five annotations to the solutions produced by the other groups.

\section{Usability}

The old Web-browsers could not handle the frames in the way Dyn3W required. The "server error" messages caused a lot of frustration especially to those students who participated from outside the university. Furthermore, the possibility of scrolling each frame of the page separately was not obvious to all students. 


\section{Scaffolding argumentation and annotation}

Students gave more "A good feature" (277) annotations than " $A$ weak feature" (167) ones. All in all 444 annotations were given by 76 students so each of them wrote on an average 5.84 annotations. In other words, the students typically gave one annotation more than was required for the extra points. The most used source for argument was "Other source" (95.5 pct). The other types for argument were based on the course material. As in the CAI Fall 1996 course (see 4.3), the same hesitation to use verifiable sources appeared. Perhaps this problem can be overcome with more support for the writing process of the annotation. One possibility to increase process support is that the system will reflect the choice of annotation type by giving the user a set of predefined questions that need to be answered for that kind of annotation type. This hypothesis will be tested in the next version of Dyn3W.

\section{DISCUSSION AND FUTURE PLANS}

Already a preliminary analysis of our experiences so far has given us confidence that systems like ours are useful in promoting discussion on university level courses, thus being an important part of the virtual campus of tomorrow. However, computer conferencing will not succeed without mindful planning. As we have shown in this paper, several intertwined dimensions of use must be carefully taken into account in planning and running a course. What follows is a partial list of issues we have learned that should be considered in arranging the next courses using the systems:

- Various modes of collaboration and utilization of the system should be supported. Both forum type public discussions and small group private work situations are needed. In our current courses there has typically been one discussion area dedicated to familiarization with the system, and on some courses we have also had an area for free discussion after the credit discussion period has ended. In addition, we see the need for private areas for one-to-one teacher-student discussion within the conferencing framework. This is an extension we intend to provide in the next courses.

- Our (see also Kurland \& Barber, 1996) data on the use of conferencing systems has shown that annotating and discussion should be tightly coupled with other activities such as construction of reports or other artifacts.

- If the system is to be used to support small group activities, some kind of positive interdependence (Salomon, 1992) must be established within the groups, if good results are hoped for. Evidently, the teacher can have various other goals for using computer conferencing besides small group work. Moreover, there will always be "lurkers" (students not participating by adding annotations but only reading them) who will learn from following the discussion. However, based on our experiences reported in this paper, our overall recommendation is that our busy students will not find the time to use 
these systems if interdependent group situations are not established (more of these techniques in the connection to computer conferencing, see e.g. Klemm (1995)).

From the technical side, the number of annotations seems to increase very easily to proportions that are not manageable for the student - some kind of assistance is needed also in this respect. We have plans for augmenting our systems with a search facility and some kind of visualizations of the annotation space, e.g. using 3D and color techniques.

\section{Acknowledgements}

The authors want to thank Päivi Majaranta and Jouni Salonen for fruitful discussions during the project. An early version of the $3 \mathrm{Wcomments} \mathrm{system} \mathrm{was}$ designed and implemented by Sami Lehtonen, Päivi Majaranta, and Ari Viljakainen, after which Päivi Majaranta extended the 3 Wcomments system for the $\mathrm{HCI}$ course described in this paper. The Dyn $3 \mathrm{~W}$ system has been designed and implemented by Timo Niemirepo. We also want to thank Professor Kari-Jouko Räihä and Aulikki Hyrskykari for using our prototypes on their courses.

\section{REFERENCES}

Chaplin, D (1996) Creating web communities. CMC Magazine, May 1996. In electronic form: http://www. december.com/cmc/mag/1996/may/ chaplin.html

Collis, B. (1994) Collaborative learning and CSCW: research perspectives for internetworked educational environments. In Lewis, R., Mendeisohn, P., (eds.), Lessons from learning. North-Holland, 81-104.

Klemm, W.R. (1995) Computer conferencing as a cooperative learning environment. Cooperative learning \& College Teaching 5, 3, Spring 1995. In electronic form: http: //www. cvm. tamu .edu/ vaph/klemm/cl.html

Klemm, W. R. \& Snell, J. R. (1996) Enriching Computer-Mediated Group Learning by Coupling Constructivism with Collaborative Learning. Journal of Instructional Science and Technology 1, 2, March 1996. In electronic form: ht tp: //www.usq.edu.au/electpub/e-jist/kl emm.htm

Klemm, W. R. \& Snell, J. R. (1994) Teaching via networked computers: what's the best medium? T.H.E. Journal 22, 3, October 1994. In electronic form: ht tp ://www.cvm. tamu.edu/ vaph/klemm/thej .html

Kurland, T. \& Barber, P. (1996) User requirements from a group perspective: the case of distance learning mediated by computer conferencing. In Thomas, $P$. (ed.), CSCW Requirements and Evaluation. Springer-Verlag, 57-74.

Laurillard, D. (1993) Rethinking university teaching: a framework for the effective use of educational technology. Routledge, London.

Mason, R. (1991) Methodologies for evaluating applications of computer conferencing. In Kaye, A.R. (ed.), Collaborative learning through computer conferencing. Springer Verlag. 
Mayes, J.T. \& Neilson, I. (1995) Leaming from other people's dialogues: questions about computer-based answers. In Collis, B., Davies, G. (eds.), Innovative adult learning with innovative technologies. Elsevier, 31-47.

Newman, D. R., Webb, B. \& Cochrane, C. (1995) A content analysis method to measure critical thinking in face-to-face and computer supported group learning. IPCT-J, 3(2), 56-77.

O'Neill, D. K., Edelson, D. C., Gomez, L. M., \& D'Amico, L. (1995) Learning to weave collaborative hypermedia into classroom practice. In J.L. Schnase \& Cunnius, E. L. (Eds.), Proceedings of CSCL '95: The First International Conference on Computer Support for Collaborative Learning, October 17-20, 1995, Bloomington, Indiana. Hillsdale, NJ: Erlbaum. In electronic form: http: //www. covis .nwu .edu/Papers/CSCL95/

CSCL95_weaving.html

Reeves, T.C. (1997) A model of the effective dimensions of interactive learming on the World Wide Web. In the Proceedings of ITK-97: Interaktiivinen Teknologia Koulutuksessa (Interactive Technology in Education) Aulanko, Hämeenlinna, Finland, April 1997.

Salomon, G. (1992) What does the design of effective CSCL require and how do we study its effects? Proc. CSCL'92, ACM SIGCUE Outlook, 21, 3 (Spring 1992), 62-68.

Scardamalia, M. \& Bereiter, C. (1993) Technologies for knowledge-building discourse. Communications of the ACM, 36(5), 37-41.

Turns, J., Mistree, F., Rosen, D., Allen, J.K., Gudzial, M. \& Carlson, D. (1995) A collaborative multimedia design environment. In Maurer, $H$. (ed.), ED-MEDIA 95 - Proceedings of World Conference on Educational Multimedia and Hypermedia, Graz, Austria, June 17-21, AACE, 654-659.

Turoff, M. (1991) Computer-Mediated Communication Requirements for Group Support. Journal of Organizational Computing 1,1, 85-113.

Verdejo, M.F., Abad, M.T. \& Barros, B. (1996) Modelling groupware for computer-supported collaborative learning. Paper presented at IFIP TC 3.6 Working Conference on "Collaborative Learning and Work", Vienna, Austria, September 1996.

Woolley, D.R. (1997) Conferencing on the World Wide Web. In electronic form: ht tp://freenet.msp.mn. us/people/drwool/webconf .html

Yerion, K.A. \& Rinehart, J.A. (1995) Guidelines for collaborative learning in computer science. SIGCSE Bulletin 27, 4, December 1995, 29-34.

\section{BIOGRAPHIES}

Pentti Hietala and Saila Ovaska are Lecturers, and Timo Niemirepo is an Assistant at the Department of Computer Science, University of Tampere. 